\title{
LA CERTIFICACIÓN PROFESIONAL Y LA CAPACITACIÓN, COMO APOYO AL CONTADOR PÚBLICO EN LAS COMPETENCIAS QUE LE REQUIERE EL MERCADO LABORAL
}

PROFESSIONAL CERTIFICATION AND TRAINING, AS SUPPORT TO THE PUBLIC COUNTER IN THE COMPETENCES REQUIRED BY THE LABOR MARKET

Dra. María Antonieta Monserrat Vera Muñoz ${ }^{a}$

Dra. Rafaela Martínez Méndez ${ }^{\text {b }}$

Dr. José Gerardo Serafín Martínez Méndez ${ }^{\mathrm{c}}$

\author{
${ }^{a}$ Benemérita Universidad Autónoma de Puebla \\ Facultad de Contaduría Pública, monseveram@hotmail.com \\ ${ }^{\mathrm{b}}$ Benemérita Universidad Autónoma de Puebla \\ Facultad de Contaduría Pública, rafaela72280@hotmail.com \\ ${ }^{c}$ Benemérita Universidad Autónoma de Puebla \\ Facultad de Contaduría Pública, gerver61@yahoo.com.mx
}

\section{RESUMEN}

El mercado laboral exige competencias a los colaboradores de las empresas y estas no se construyen por sí solas en los individuos, hay que generarlas y mantenerlas. Por lo que la investigación persigue como objetivo Indagar el apoyo que la capacitación y la certificación profesional aportan al Contador Público para adquirir y fortalecer las competencias que le son requeridas por el mercado laboral. Considerando una estrategia metodológica cualitativa, para examinar conceptos teóricos y contrastarlos con la información obtenida en el trabajo de campo e identificar la interacción y relación entre la capacitación y certificación profesional con las competencias. Teniendo como limitante que los sujetos de estudio se ubican en la ciudad de Puebla. Los resultados muestran de manera particular a la capacitación conjuntamente con la certificación en los profesionales de la Contaduría Pública como apoyo para acumular competencias que les permitan enfrentar exitosamente el mercado laboral. Concluyendo que los empleadores denotan preferencia especificas por algunas competencias.

\section{PALABRAS CLAVE:}

Competencias; Capacitación; Certificación profesional; Profesionales de la Contaduría Pública. 


\begin{abstract}
The labor market demands competences from the collaborators of the companies and these are not constructed by themselves in the individuals, they are generated and maintained. Therefore, the research pursues as an objective to investigate the support that training and professional certification provide to the Public Accountant to acquire and strengthen the skills required by the labor market. Considering a qualitative methodological strategy, to examine theoretical concepts and contrast them with the information obtained in the fieldwork and identify the interaction and relationship between training and professional certification with the competences. Having as limitation that the study subjects are located in the city of Puebla. The results show in a particular way the training together with the certification in the Public Accounting professionals as support to accumulate competences that allow them to successfully face the labor market. Concluding that employers denote specific preferences for some competences.
\end{abstract}

\title{
KEYWORDS:
}

Competences; Training; Professional certification; Professionals of the Public Accounting.

\section{INTRODUCCIÓN}

El mercado laboral, ante un mundo globalizado, ha transformado sus exigencias y en la actualidad requiere que los Contadores Públicos para insertarse en él tengan competencias sólidas y adecuadas, generales y específicas para área económicoadministrativa.

El presente trabajo se busca indagar la importancia de la relación entre la capacitación y certificación profesional para la adquisición y conservación de las competencias exigidas por el mercado laboral que les son requeridas a los profesionales de las áreas económico-administrativas, en específico a los Contadores Públicos.

Para abordar lo anterior, el trabajo se integra de una revisión literaria que permite definir las competencias, sus tipos y particularizar en las requeridas para el área de la contaduría pública por el mercado laboral, capacitación, certificación profesional y profesionales de contaduría pública. Posteriormente se incluye la metodología utilizada, los resultados y discusión de los mismos, finalizando con conclusiones y referencias.

\section{PLANTEAMIENTO}

Hablar de competencias constituye un gran reto, debido a que estas se involucran en diversos temas relacionados con los seres humanos, como el ámbito laboral, lo que nos lleva a visualizar un campo aún muy amplio respecto al tema y obliga a seguir delimitando, para aterrizar el trabajo en los Contadores Públicos; lo anterior está en la

Vera, M. A. M., Martínez Méndez, R. \& Martínez Méndez J. G. S. 
misma línea de los desafíos empresariales actuales en producción, servicios, mercado y que, ante la globalización, las empresas necesitan buscar la manera de salir avante y mantenerse en el mercado, el final de la búsqueda finaliza cuando la empresa encuentra a las personas adecuadas que le apoyen para enfrentar esos retos.

Complementando lo anterior, la fuerza de las empresas proviene de las personas por lo que es importante conformar un buen grupo de colaboradores que le den a la empresa la fuerza que necesita.

De ahí que las personas que tengan interés en formar parte de las empresas conozcan que competencias se les están requiriendo y valoren si cuentan o no con ellas. Ya identificadas en la literatura sobre el tema, las competencias que le son requeridas a los Contadores Públicos, estos tendrán que darse a la tarea de valorar con cuáles ya cuentan y en caso de no tenerlas formarlas, entre otras vías, por medio de la capacitación y la certificación profesional.

En otro escenario, los Contadores Públicos que ya se encuentren inmersos en las empresas para permanecer en ellas o poder mejorar su situación laboral en las mismas, también tienen que diagnosticar qué competencias necesitan e involucrarse con la capacitación necesaria para adquirirlas y de ser necesario certificarse profesionalmente.

Con base en lo anterior, consideramos como variables de investigación: competencias, capacitación y certificación profesional.

\section{OBJETIVOS}

\section{General.}

Indagar el apoyo que la capacitación y la certificación profesional aportan al Contador Público para adquirir y fortalecer las competencias que le son requeridas por el mercado laboral.

\section{Específicos}

- Definir competencias.

- Investigar cuáles son las competencias que el mercado laboral requiere a los Contadores Públicos.

- Especificar la capacitación que requiere el Contador Público.

- Indagar el objetivo de la certificación profesional.

- Indagar lo que requiere el Contador Público para la certificación profesional.

- Indagar lo que le aporta al Contador Público la certificación profesional.

Vera, M. A. M., Martínez Méndez, R. \& Martínez Méndez J. G. S. 


\section{MARCO TEÓRICO CONCEPTUAL}

Las personas que prestan sus servicios en una empresa en el transcurrir del tiempo han sido llamados de diversas formas, por ejemplo, personal, colaboradores, recursos humanos y actualmente capital humano, mismo que para Para Alles (2010), el capital humano se compone de todas las capacidades individuales, los conocimientos, las destrezas y la experiencia de los empleados y gerentes de la empresa. Farías (2013) define al capital humano como el grupo de personas que contribuyen a la consecución de un fin determinado, como parte de la organización. Carrión (2013) Se entiende por capital humano al conocimiento que posee cada individuo y en la medida que el individuo incremente sus conocimientos, se incrementa su capital humano. Y Chiavenato (2017), menciona que el capital humano, es el capital de las personas integrado por talentos y de competencias.

El capital humano se integra de diferentes elementos como: cualidades, conocimientos, salud, virtudes, habilidades, enseñanza, destrezas, competencias y otros atributos que poseen los individuos.

A las empresas no es suficiente tener personas; es necesaria una plataforma que sirva de base y un clima que impulse a las personas y utilice los talentos existentes en ellas. De este modo, el capital humano estará constituido básicamente por los talentos y competencias de las personas. Su utilización plena requiere una estructura organizacional adecuada y una cultura democrática e impulsora.

La gestión del capital humano (recursos humanos) es prudente que adopte un modelo que le permita identificar y analizar las conductas observables y evaluables denominadas competencias.

\section{IV.I Competencias}

Para Tejada (2005), las competencias son el conjunto de saberes (saber, saber hacer, saber estar y saber ser conocimientos, procedimientos y actitudes) combinados, coordinados e integrados en el ejercicio profesional. El dominio de estos saberes le hace capaz de actuar a un individuo con eficiencia en una situación profesional.

Para Irigoin (2002), competencia es la gestión integrada de conocimientos habilidades y actitudes que se accionan para un desempeño adecuado, ya sea en el ámbito académico o laboral. Las competencias son los conocimientos, habilidades, actitudes, intereses, rasgos, valores u otras características personales esenciales para desempeñar las actividades y que diferencian el desempeño de las personas (Chiavenato, 2017).

Siguiendo a Chiavenato (2017), la competencia de una persona es la capacidad de

Vera, M. A. M., Martínez Méndez, R. \& Martínez Méndez J. G. S. 
actuar en diversas situaciones para crear activos, tanto tangibles como intangibles.

Las competencias son características subyacentes a las personas y se relacionan a su buen desempeño, enfocándonos a la parte laboral se puede decir, que competencias son las características subyacentes a las personas que se relacionan con su buen desempeño en su puesto laboral.

Las competencias para los que realizan el trabajo son habilidades, actitudes, intereses, rasgos, valores, y capacidad, que marcan diferencia en el comportamiento y desempeño de las personas.

Hoy día, las competencias ocupan a las empresas y se han convertido en un elemento a considerar como parte de las exigencias a sus colaboradores. Al respecto se especula que las competencias con mayor importancia para el futuro son las competencias críticas, aquellas que identifican las claves del éxito de las personas, por su desempeño en ciertas funciones y situaciones.

Las competencias de las personas se construyen, desarrollan o se generan por diferentes razones, entre las que se encuentran: conocimientos, actitudes, valores, motivaciones, necesidades, gustos y preferencias.

Es prudente comentar que, las competencias deben ser medibles para poder cuantificarlas y relacionarlas con el desempeño de las personas en diferentes ámbitos como el académico, laboral, deportivo, etc.

\section{IV.II Organismos que participan en la determinación de competencias}

México es el primer país de Latinoamérica que participa en la formación de competencias laborales con la implementación de Consejo de Normalización y Certificación de Competencia Laboral en al año de 1995. La Comisión Económica para América Latina -CEPAL-, en el año 2005, planteó una serie de estrategias y procedimientos encaminados a desarrollar un sistema de certificación de competencias para América Latina, de forma que se incentiven las dinámicas relacionadas con la adquisición de trabajo y la productividad de los trabajadores (Linares y Suárez, 2016).

\section{IV.III Competencias para la Contaduría publica}

La International Federation of Accountants (IFAC), organismo internacional, que su objetivo es servir al interés público mediante el fortalecimiento de la profesión y contribuyendo al desarrollo de economías internacionales, ha establecido el Consejo de Normas Internacionales de Formación en Contabilidad, para establecer

Vera, M. A. M., Martínez Méndez, R. \& Martínez Méndez J. G. S. 
lineamientos en tres áreas, una de ellas es Normas Internacionales de Formación para Contadores Profesionales/International Education Standars/IES), tiene la encomienda de establecer Estándares Internacionales, entre otros, de auditoría, ética, contabilidad, educación, y puede considerarse a estos como un referente, obedeciendo a que en este documento aparece el término de competencia (Valero, G., Patiño, R. y Duque, O., 2013). Contribuye también la American Accounting Association (AAA), para el año de 1984 nombró un comité de profesionales con el propósito de revisar la estructura formativa de los profesionales en el área contable en los E.E. U.U. En lo que respecta a Europa se creó Common Content Project con el propósito de unificar los requisitos que deben reunir los Contadores (Linares y Suárez, 2016).

La Ley 43 de 1990 reglamenta la profesión del Contador Público, versa sobre la profesión, su ejercicio, vigilancia y dirección y ética en un total de 75 artículos.

En México, el organismo más representativo es el Instituto Mexicano de Contadores Públicos (IMPC), fundado en 1925; en 1955 adquiere su nombre actual y para 1977 es reconocido como el órgano rector de la Contaduría Pública.

Los organismos citados con antelación buscan, en común, apoyar el desempeño del profesional de la Contaduría Pública para enfrentar las exigencias del mercado laboral. Señalan como criterios para las competencias de los Contadores Públicos, áreas de servicios en las que se desempeña el Contador y para cada una de ellas se deben desarrollar conocimientos y habilidades cognitivas, de comportamiento, integradoras y multidisciplinarias, en un entorno de valores, actitudes y conducta ética del profesional.

Ratificando lo anterior, Cordúa (2000) afirma que, en las empresas, cada vez más demandan a sus colaboradores no sólo conocimientos sino un conjunto de competencias Genéricas; el mismo autor identifica tres tipos de competencias laborales: competencias genéricas, competencias técnicas y competencias específicas. Ernst \& Joung Consultores proponen: competencias diferenciadoras y competencias umbral.

Respecto a los criterios que apoyan las competencias para el Contador Público, apreciamos una cobertura para las distintas áreas de actuación con enfoque integral enmarcado en una conducta ética a la luz del Código de Ética Profesional.

En la tabla 1 se realiza la presentación de competencias bajo dos ópticas, la de Valera (2009) y la de Ernst \& Joung (2017), autores que abordan las competencias para la profesión contable.

Vera, M. A. M., Martínez Méndez, R. \& Martínez Méndez J. G. S. 
Tabla 1

Propuestas de competencias

\begin{tabular}{|l|l|l|}
\hline Valera & Ernst \& Joung Consultores & Puntos comunes \\
\hline $\begin{array}{l}\text { Competencia } \\
\text { comunicativa }\end{array}$ & Comunicación & $\begin{array}{l}\text { Expresión oral y escrita } \\
\text { Trabajo en equipo } \\
\text { Liderazgo } \\
\text { Relaciones públicas } \\
\text { Creatividad }\end{array}$ \\
\hline Competencia cognitiva & Gerencia/gestión & \\
\hline $\begin{array}{l}\text { Competencia indagativa } \\
\text { argumentativa }\end{array}$ & Influencia & \\
\cline { 1 - 2 } $\begin{array}{l}\text { Competencia } \\
\text { investigativa }\end{array}$ & Solución e innovación & \\
\hline & Sogro y acción & \\
\hline
\end{tabular}

Fuente: elaboración propia con base en Valera (2009).

Como se aprecia, existen puntos comunes en las propuestas de la Tabla 1 que se incluyen en la última columna, pero de una forma sencilla podemos comentar, sobre una base empírica, que las empresas exigen competencias en general que se retoman según el lugar a ocupar en la empresa y se pueden mencionar las siguientes: aprender a aprender, comunicación y colaboración, raciocinio creativo y resolución de problemas, conocimiento tecnológico, conocimiento de negocios globales, desarrollo de liderazgo y administración de la carrera (en algunos casos).

Las competencias generan beneficios a las personas que las adquieren tales como: competitividad, ayuda para maximizar el rendimiento individual y el rendimiento colectivo, conocer capacidades que se mantenían pasivas, mejorar el desempeño y la productividad y ayuda para definir una ruta clara para el desarrollo de cada persona. Valera (2009) señala las competencias específicas para los profesionales de la disciplina contable que se integran en la tabla 2. 
Tabla 2

Competencias propias de los profesionales del área contable

\begin{tabular}{|c|c|c|}
\hline Competencia & Descripción & Aplicación \\
\hline Comunicativa & $\begin{array}{l}\text { Implica desempeñarse } \\
\text { adecuadamente en distintas } \\
\text { situaciones comunicativas. Tener } \\
\text { facilidad de comunicación oral y } \\
\text { escrita, trabajo en equipo y } \\
\text { liderazgo, capacidad de desarrollar } \\
\text { relaciones públicas y suministrar } \\
\text { datos de calidad, oportunos, } \\
\text { comprensibles y transparentes. }\end{array}$ & $\begin{array}{l}\text { Con esta competencia se } \\
\text { promueve la unidad entre lo } \\
\text { cognitivo y lo afectivo, las } \\
\text { palabras (lenguaje verbal) } \\
\text { corresponden a lo cognitivo y } \\
\text { los gestos (leguaje gesticular o } \\
\text { facial) corresponden a lo } \\
\text { afectivo. }\end{array}$ \\
\hline Cognitiva & $\begin{array}{l}\text { Esta competencia exige tener } \\
\text { disposición y capacidad para la } \\
\text { gestión de proyectos: iniciativa, } \\
\text { creatividad, adaptación al cambio, } \\
\text { formación jurídica } \\
\text { independencia. }\end{array}$ & $\begin{array}{l}\text { Estar competencia exige } \\
\text { demostrar conocimientos } \\
\text { sólidos y actuales, manejo de } \\
\text { leyes y demás disposiciones } \\
\text { fiscales }\end{array}$ \\
\hline Indagativa & $\begin{array}{l}\text { Es saber identificar, acceder y } \\
\text { manejar fuentes de información } \\
\text { según los requerimientos y } \\
\text { mantener una actitud crítica y } \\
\text { reflexiva frente a hechos o } \\
\text { fenómenos que incluye: dominio } \\
\text { de tecnologías de la información, } \\
\text { analista financiero, diseño de } \\
\text { sistemas contables y de control } \\
\text { interno, manejo de la } \\
\text { documentación a primaria, } \\
\text { pertinencia y pertenencia. }\end{array}$ & $\begin{array}{l}\text { Para demostrar tener esta } \\
\text { competencia se debe estar } \\
\text { capacitado en el manejo de } \\
\text { computadora y paquetes } \\
\text { contables y fiscales que se } \\
\text { manejan por computadora para } \\
\text { cumplir con los requerimientos } \\
\text { fiscales actuales }\end{array}$ \\
\hline Argumentativa & $\begin{array}{l}\text { Requiere de fijar posiciones claras } \\
\text { y sustentarlas adecuadamente, } \\
\text { buen negociador, facilitador de la } \\
\text { toma de decisiones. }\end{array}$ & 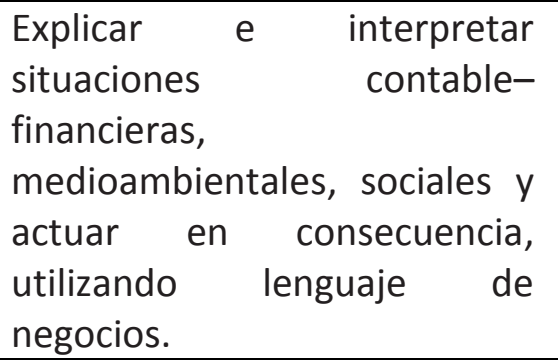 \\
\hline
\end{tabular}

Vera, M. A. M., Martínez Méndez, R. \& Martínez Méndez J. G. S. 


\begin{tabular}{|c|c|c|}
\hline Propositiva & $\begin{array}{l}\text { Identificar, formular problemas, } \\
\text { desarrollar y presentar propuestas } \\
\text { de solución para situaciones } \\
\text { problemáticas de su profesión. }\end{array}$ & $\begin{array}{l}\text { Formular un banco de } \\
\text { problemas inherentes a su } \\
\text { profesión, atendiendo a las } \\
\text { características de su entorno } \\
\text { laboral; conjugación del } \\
\text { desarrollo teórico con } \\
\text { capacidades, habilidades y } \\
\text { recursos para atender las } \\
\text { necesidades de la sociedad, } \\
\text { resolución de problemas } \\
\text { dados en su ámbito } \\
\text { profesional utilizando avances } \\
\text { científico-técnicos de su } \\
\text { ciencia y asumir } \\
\text { responsabilidad frente a las } \\
\text { soluciones propuestas. }\end{array}$ \\
\hline Investigativa & $\begin{array}{l}\text { Uso de métodos de investigación } \\
\text { científica en su esfera de } \\
\text { actuación, participar en eventos } \\
\text { científicos en los que muestre los } \\
\text { resultados obtenidos en la } \\
\text { resolución de problemas de su } \\
\text { ámbito profesional, cursar estudios } \\
\text { de postgrado para la actualización } \\
\text { en los principales avances } \\
\text { científico-técnicos de su ciencia y } \\
\text { obtener grados científicos. }\end{array}$ & $\begin{array}{l}\text { Para ostentar está } \\
\text { competencia, hay involucrarse } \\
\text { con la investigación y con los } \\
\text { estudios de posgrado, además } \\
\text { de la educación continua. }\end{array}$ \\
\hline
\end{tabular}

Fuente: elaboración propia con base en Valera (2009).

Relacionada con la última competencia de la Tabla 2 está la educación continua, concerniente con la certificación que el Código Fiscal de la Federación (CFF) en el artículo 52 Fracción primera y el artículo 52 del Reglamento del mismo Código señalan cuando el C.P. se involucra en práctica de la Auditoria de Estados Financieros con alcance Fiscal.

Las competencias descritas en la tabla 2, dentro de las que se encuentran, entre otras, liderazgo, transparencia, facilidad al administrar datos, gestión de proyectos, buen negociador, resolución de problemas con avances científico-técnicos, se amalgaman para integrar los dos componentes de las competencias; primer componente (conocimientos) y segundo componente (habilidades/cualidades) se ilustran en la figura 1.

Vera, M. A. M., Martínez Méndez, R. \& Martínez Méndez J. G. S. 


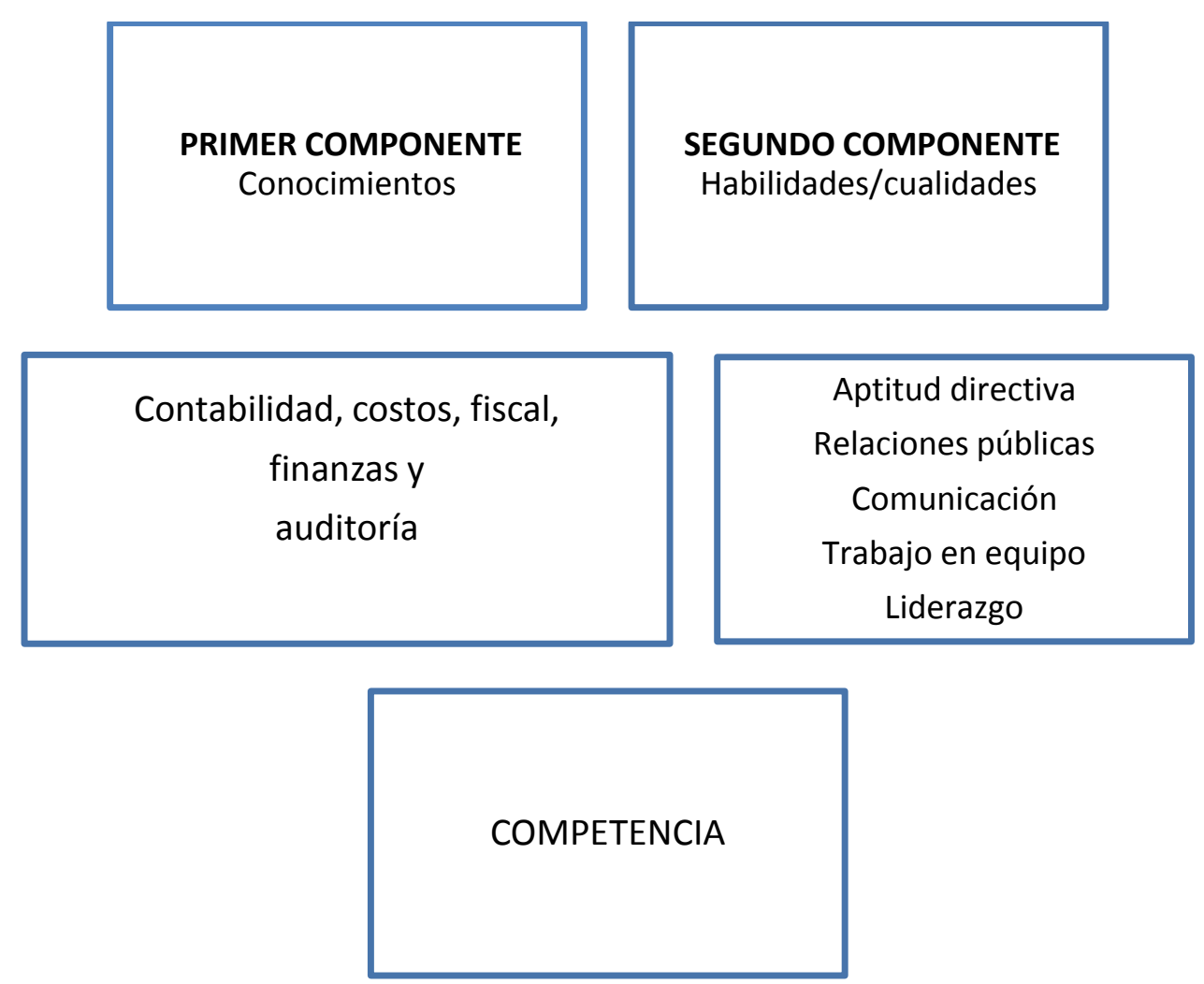

Figura1. Componentes de las competencias. Elaboración propia con base en Ernst \& Joung Consultores, (2017).

En la figura 1 se incluyen conocimientos en el área contable, así como las habilidades y cualidades que al Contador Público le son necesarias para el ejercicio como profesional de la contaduría pública en diferentes áreas de trabajo.

Una competencia no es producto de la casualidad ni surge espontáneamente; se crea y se logra a través de un largo proceso de aprendizaje. Se relaciona con la capacitación y la certificación profesional, debido a que ambas promueven y exigen conocimientos y habilidades que el Contador aplica en el ejercicio de la profesión.

\section{IV.IV Educación}

La educación es vital al abordar el tema de competencias; a la educación se le conoce como: aquello que el ser humano recibe del ambiente social durante su existencia, considerando normas y valores.

Se puede señalar que la educación es la preparación para la vida. Existen diversos tipos de educación: social, religiosa, cultural, política, moral y profesional.

En el presente trabajo nos referimos a la educación profesional entendida como: la educación institucionalizada o no, que busca preparar a la persona para la vida 
profesional.

La educación profesional comprende tres etapas: formación profesional, desarrollo profesional y capacitación.

La formación profesional se obtiene con un programa a largo plazo, cursando una licenciatura. Por ejemplo, licenciatura en Contaduría Pública. El desarrollo profesional se adquiere con un programa a mediano plazo, por ejemplo, una especialidad.

\section{IV.V Capacitación}

La capacitación es en un corto plazo y algunos autores como Gary Dessler, Chiavenato, Martínez \& Martínez y NAFINSA, nos apoyan para comentar que "la capacitación es un conjunto de actividades mediante las cuales las personas adquieren y desarrollan: conocimientos, habilidades, aptitudes y competencias que les facilita realizar sus actividades laborales".

Para Farías (2013), la capacitación se integra por la transmisión de conocimientos y habilidades a través de enseñanza teórica, ejercicios prácticos y diversos apoyos. La capacitación implica: transmisión de conocimientos, desarrollo de habilidades, desarrollo o modificación de actitudes y desarrollo de conceptos.

Para poner en práctica la capacitación, las empresas siguen un ciclo Chiavenato (2017). Que se ilustra en la Figura 2.

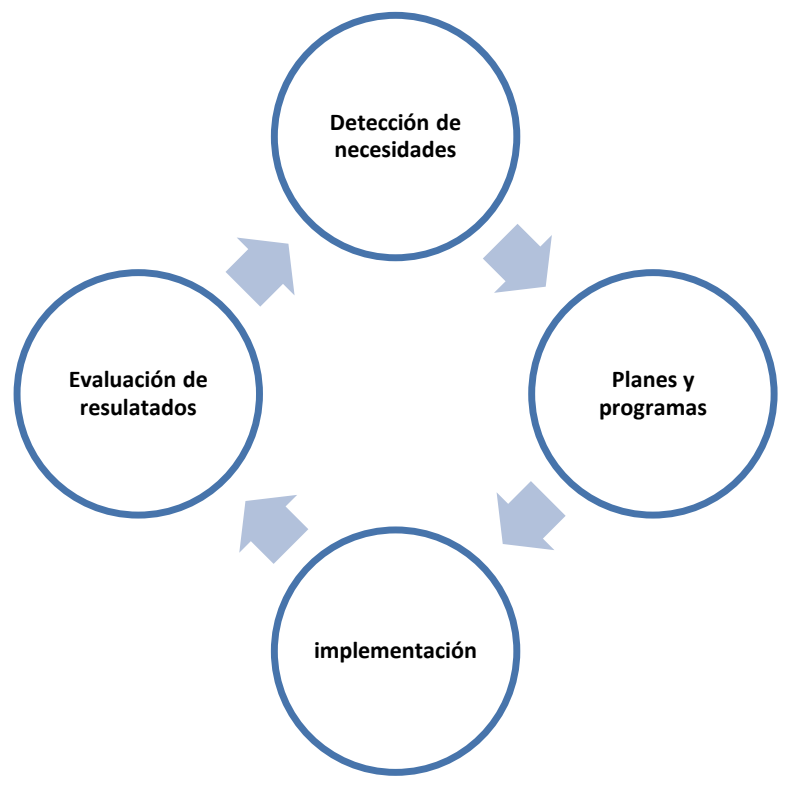

Figura 2. Ciclo de capacitación. Elaboración propia con base en Chiavenato (2017).

Vera, M. A. M., Martínez Méndez, R. \& Martínez Méndez J. G. S. 
El punto inicial del ciclo de capacitación Figura 2: detección de necesidades es vital para éxito y aprovechamiento de la capacitación, y de esa forma ver a la capacitación por lo que realmente representa una inversión y no un gasto.

Finalmente, comentamos que la capacitación está ligada estrechamente con las competencias al apoyar a iniciarlas, madurarlas y/o mantenerlas.

\section{IV.VII Certificación Profesional}

Los Contadores Públicos cursan la licenciatura en diversas instituciones educativas, en las que cada una de ellas tiene su propio programa y alternativas de titulación, lo que favorece la falta de uniformidad y por consiguiente diferencias en la preparación de los egresados que pueden ser importantes para el ejercicio profesional; aunado a lo anterior, nuestro país ha participado en la firma de tratados internacionales que exigen cumplir requisitos a los profesionales de la contaduría para poder participar en reciprocidad respecto a la prestación de servicios profesionales. Para hacer frente a lo anteriormente referido surge la Certificación Profesional el $1^{\circ}$ de mayo de 1998, bajo la responsabilidad del IMCP.

El objetivo de la Certificación Profesional es unificar a la preparación de los Contadores Públicos con un proceso de calidad para sustentar la validez y actualización de los conocimientos técnicos teóricos de la profesión, así como la experiencia para el desarrollo de las actividades profesionales. Para acreditar la calidad profesional ante personas y organizaciones públicas o privadas, del Contador Público que posee los conocimientos técnico administrativos suficientes y la experiencia necesaria, para desarrollar con eficiencia las actividades propias de su profesión.

La certificación profesional es aquella que otorga un organismo no gubernamental, normalmente una organización de reconocido prestigio en el área profesional correspondiente y que debe revalidarse periódicamente. Hace constar que un profesionista posee los conocimientos, habilidades, destrezas y aptitudes exigidos para el ejercicio de una profesión determinada (Castillo, 2016).

La certificación profesional está representada por una constancia que ampara la validez y actualización de los conocimientos teórico técnicos de la Contaduría Pública y para obtenerla se requiere sustentar un examen ante una organización no gubernamental, quien otorga una calificación aprobatoria o no aprobatoria, para el Contador Público que requiere el reconocimiento profesional avalado por organismos autorizados, siempre en forma voluntaria.

Como lo establece el artículo 12 del reglamento vigente para 2018-2019, el "certificado" tendrá una validez de cuatro años, transcurridos los cuales deberá ser refrendado por el instituto, para lo cual durante el mes de abril del año de que se trate, los Contadores

Vera, M. A. M., Martínez Méndez, R. \& Martínez Méndez J. G. S. 
Públicos Certificados que deseen refrendarlo y estén colegiados, deberán presentar una solicitud acompañando las constancias anuales de cumplimiento de la Norma de Desarrollo Profesional continua (NDPC) de los últimos cuatro años, expedidas por su colegio.

Para obtener la certificación por los Contadores Públicos, el IMCP establece como criterios: presentar la solicitud correspondiente y cumplir con los requisitos establecidos en el reglamento relativo, así como presentar y aprobar el Examen Uniforme de Certificación (EUC), el cual fue elaborado por el Instituto Mexicano de Contadores Públicos, con la participación de destacados profesionales de la Contaduría Pública, en sus respectivos campos de especialización.

Las áreas de que integran certificación profesional son: contabilidad, contabilidad gubernamental, auditoría, contabilidad y auditoría gubernamental, costos, finanzas y fiscal.

Ventajas de la certificación profesional: avala los conocimientos, genera seguridad a los clientes, genera prestigio y confianza de calidad profesional, fortalece la credibilidad del trabajo, representa una competencia para acceder a puestos restringidos e incrementa la reputación profesional.

La certificación apoya a los profesionales de la Contaduría a respaldar sus competencias, lo que les ofrece una ventaja para integrarse al mercado laboral altamente competido en la profesión contable.

A partir del $1^{\circ}$ de junio de 2010 aplica el proceso de Certificación por Disciplinas, contemplando las siguientes: contabilidad gubernamental, contabilidad y auditoría gubernamental, finanzas empresariales, fiscal, normas de información financiera, en materia de la Ley Federal para la Prevención e Identificación de Operaciones con Recursos de Procedencia llícita (PLD). Los requisitos están contenidos en el artículo 4 del Reglamento de Certificación por Disciplinas.

\section{IV.VIII Profesionales de la Contaduría Pública.}

La disciplina de la Contaduría Pública satisface las necesidades de los usuarios de información que refleja el comportamiento financiero de la empresa y le es útil para tomar decisiones. Por lo que es frecuente encontrar la expresión "la contabilidad es el lenguaje de los negocios".

El profesional de la Contaduría Pública comúnmente es nombrado Contador Público (C.P.) y es la persona quien gestiona, registra y construye la contabilidad e información financiera de las empresas, respetando la valuación y presentación de cifras, de acuerdo a lo que señalan las Normas de Información Financiera (NIF).

Vera, M. A. M., Martínez Méndez, R. \& Martínez Méndez J. G. S. 
Continuando con el quehacer del C.P. podemos mencionar, en otras palabras, que se encarga de cuantificar, mediante la utilización de cuentas, la aplicación de los recursos empresariales en la actividad de la empresa y determinar los resultados de operación y la situación financiera de la misma a través de la elaboración de documentos numéricos llamados estados financieros, que son de gran utilidad para la toma de decisiones. Sin embargo, el ejercicio de la profesión contable no se limita al registro sistemático de las transacciones realizadas por la empresa y obtener información financiera, también calcula impuestos con base en la legislación fiscal, realiza proyección y presupuestación de cifras, revisa y comprueba información, entre otras actividades, utilizando los avances tecnológicos.

Por lo anteriormente comentado, podemos identificar que, para el desarrollo de la profesión contable, el C.P. necesita conjuntar diversas competencias que le apoyen en la realización de su actividad profesional. Como un profesional independiente, como colaborador en el sector público o privado, como docente o como investigador.

\section{METODOLOGÍA, TÉCNICAS Y MATERIALES EMPLEADOS}

La primera parte del trabajo es descriptiva y se integra por una construcción teórica. Esta parte se desarrolló con búsqueda de información, misma que se leyó y analizó para posteriormente sintetizar e incluir en el trabajo, lo que permitió integrar un panorama teórico bajo la óptica de diferentes autores y diferentes posturas. La segunda parte contempla el trabajo de campo con la aplicación de un cuestionario que sirvió de apoyo, complementado con la observación in situ.

Instrumento. Para realizar el trabajo de campo se procedió a construir un instrumento, considerando preguntas para los seis tipos de competencias señalados por Valera (2009) aplicables al área contable, integrándose con 40 ítems, con alternativas dicotómicas de respuesta y considerando el primen ítem como pregunta filtro.

Muestra. Para aplicar el instrumento se determinó una muestra que se integró por doscientos sesenta empleadores de una población total 21,279 empresas (Instituto de Información Estadística y Geografía [IIEG], 2018) consideradas como empleadores por las personas encargadas de la contratación de los colaboradores. Para calcular la muestra se aplicó la formula siguiente, considerando un nivel de confianza de 95\%:

$$
\mathrm{n}=\frac{\mathrm{n}_{\mathrm{o}}}{1+\frac{\mathrm{n}_{\mathrm{o}}}{\mathrm{N}}} \text { donde: } \mathrm{n}_{\mathrm{o}}=p^{*}(1-p) *\left(\frac{\mathrm{z}\left(1-\frac{\alpha}{2}\right)}{\mathrm{d}}\right)^{2}
$$

Vera, M. A. M., Martínez Méndez, R. \& Martínez Méndez J. G. S. 
Al calcular la muestra, se obtuvo un número de 263 empleadores y por redondeo se integra por 270. Las empresas que integraron la muestra pertenecen y desarrollan diversas actividades económicas.

Recolección de datos. La recolección de datos se realizó con la aplicación del cuestionario a los encargados de la contratación de colaboradores en las empresas durante los meses de agosto, septiembre, octubre y noviembre de 2018, mismo que fue elaborado con base en las seis competencias relacionadas con el área del Contador Público que incluyen, entre otros, liderazgo en la estadística, así como de transparencia, facilidad al administrar datos, gestión de proyectos, que debe ser un buen negociador, resuelvan problemas con avances científico-técnicos (Valera, 2009), obteniendo una tasa de respuesta del 100\%. Los datos recolectados se presentan en tablas y de forma gráfica, posteriormente se realizó un análisis de los mismos para poder llegar a construir las conclusiones.

Los resultados obtenidos con la aplicación del instrumento fueron trabajados con el programa Statistical Package for the Social Sciences (SPSS), se presentan a continuación, en la tabla 3 la pregunta filtro y lo que respecta a las competencias de forma gráfica, figura 3 competencia comunicativa, figura 4 competencia cognitiva, figura 5 competencia indagativa, figura 6 competencia argumentativa, figura 7 competencia propositiva y figura 8 competencia investigativa.

Tabla 3

Empleadores (Pregunta filtro)

\begin{tabular}{|l|r|r|r|r|r|}
\hline \multicolumn{2}{|c|}{ ¿Es usted empleador? } \\
\hline \multicolumn{2}{|c|}{} & Frecuencia & Porcentaje & $\begin{array}{c}\text { Porcentaje } \\
\text { válido }\end{array}$ & $\begin{array}{c}\text { Porcentaje } \\
\text { acumulado }\end{array}$ \\
\hline Válido & $\mathrm{Si}$ & 270 & 100.0 & 100.0 & 100.0 \\
\hline
\end{tabular}

Fuente: elaboración propia (2019.

Vera, M. A. M., Martínez Méndez, R. \& Martínez Méndez J. G. S. 


\section{0}

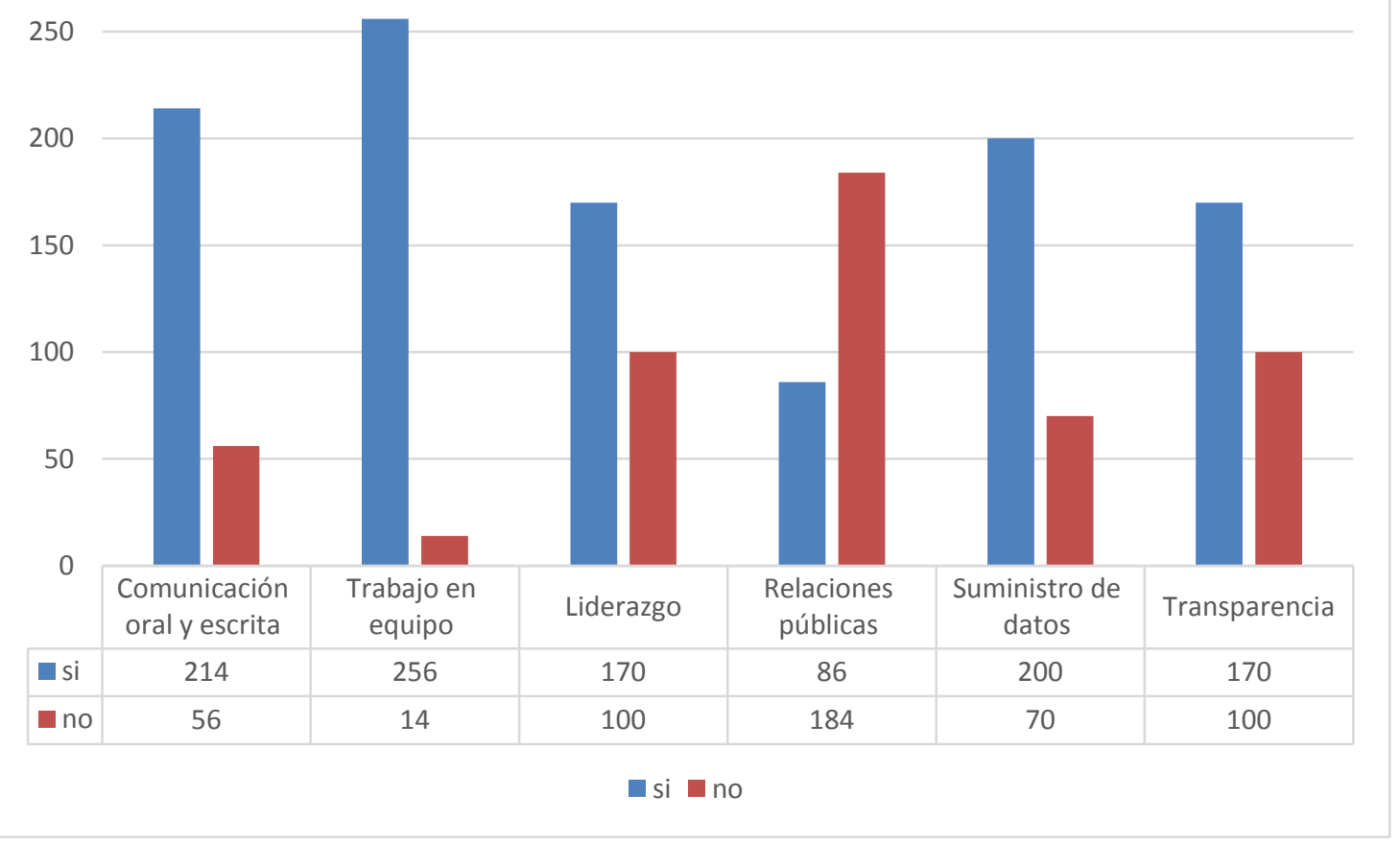

Figura 3. Competencia Comunicativa. Elaboración propia (2019.)

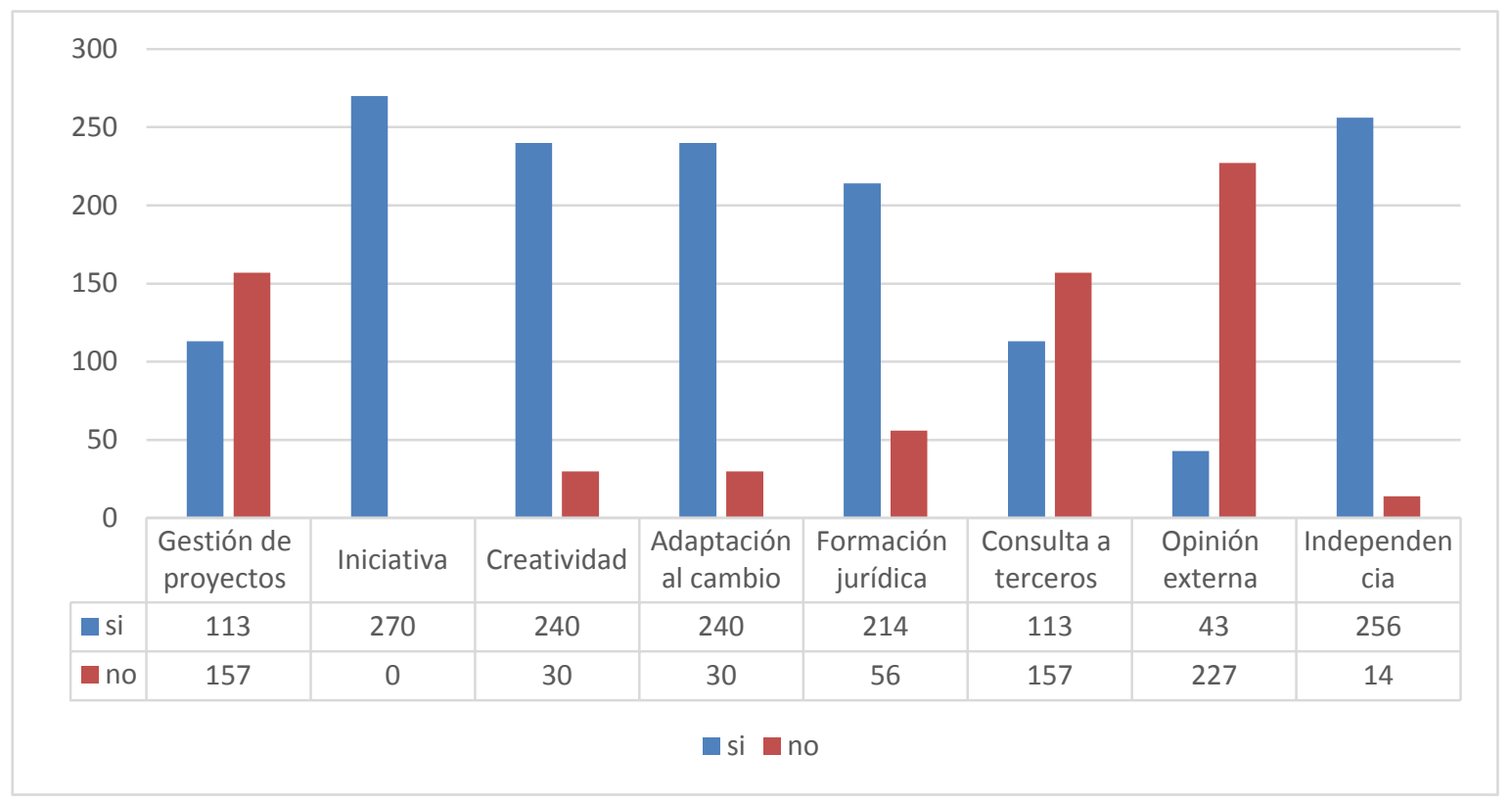

Figura 4. Competencia Cognitiva. Elaboración propia (2019.

Vera, M. A. M., Martínez Méndez, R. \& Martínez Méndez J. G. S.

La certificación profesional y la capacitación, como apoyo al contador público en las competencias que le requiere el mercado laboral. 


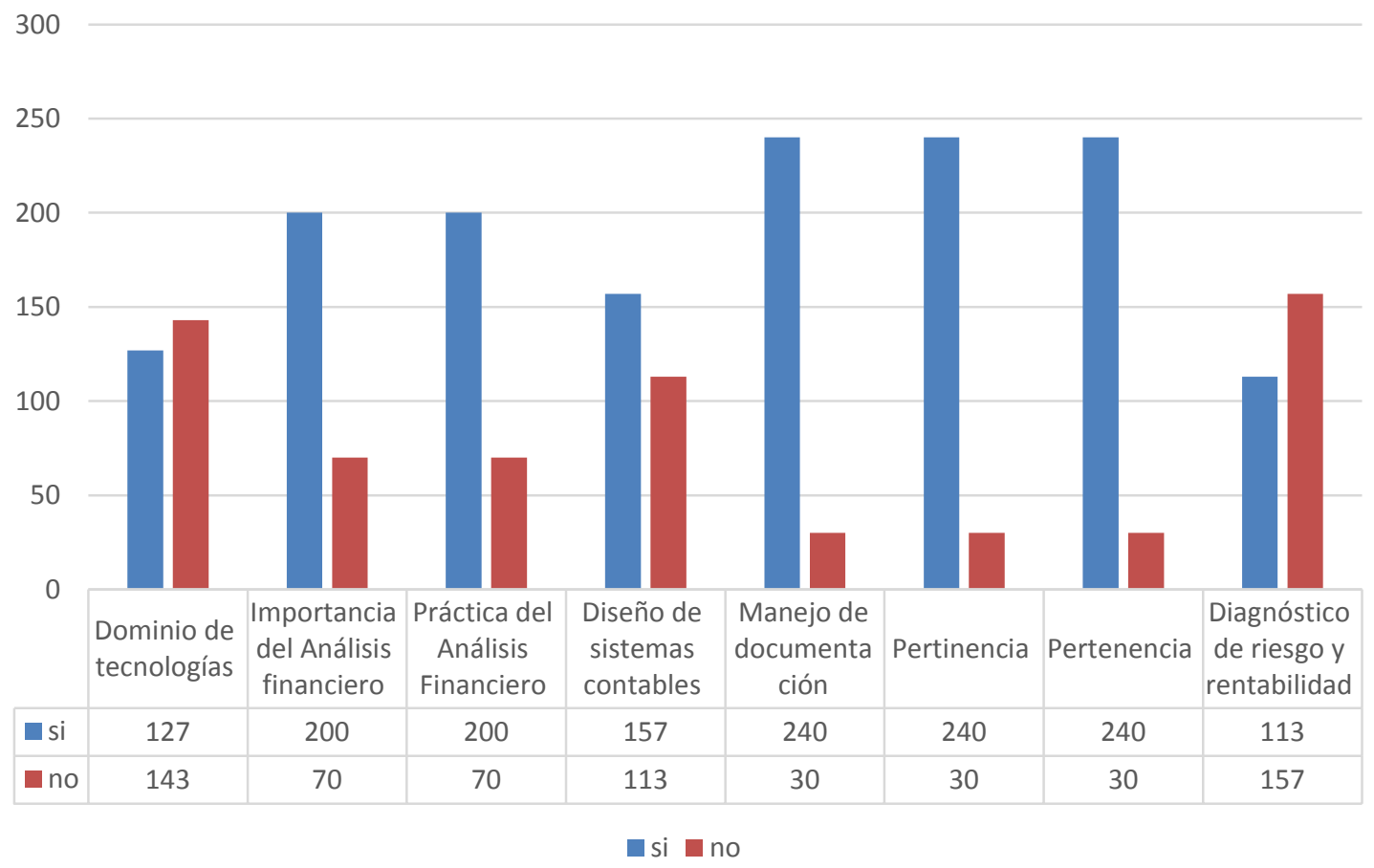

Figura 5. Competencia Indagativa. Elaboración propia (2019).

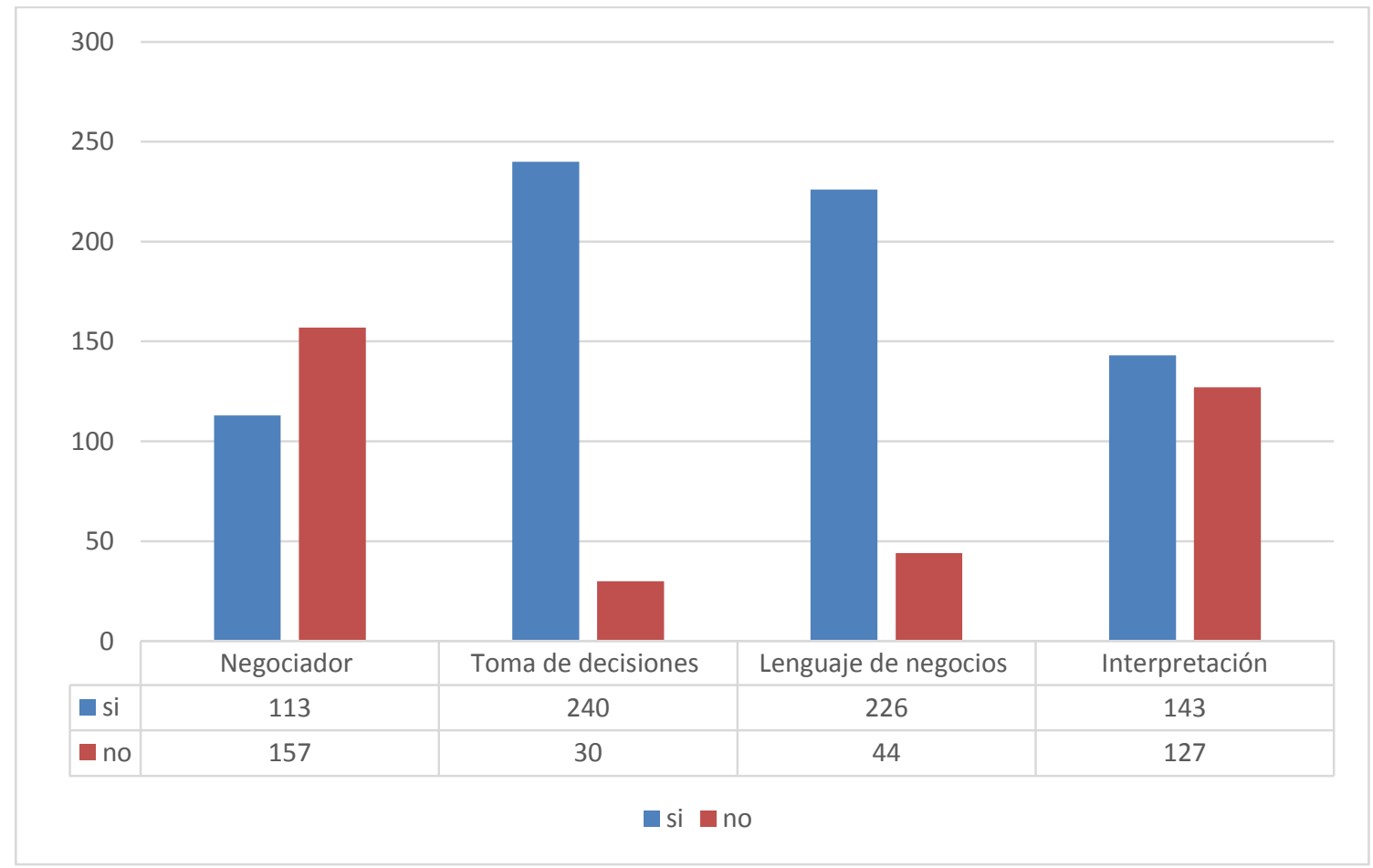

Figura 6. Competencia Argumentativa. Elaboración propia( 2019).

Vera, M. A. M., Martínez Méndez, R. \& Martínez Méndez J. G. S.

La certificación profesional y la capacitación, como apoyo al contador público en las competencias que le requiere el mercado laboral. 


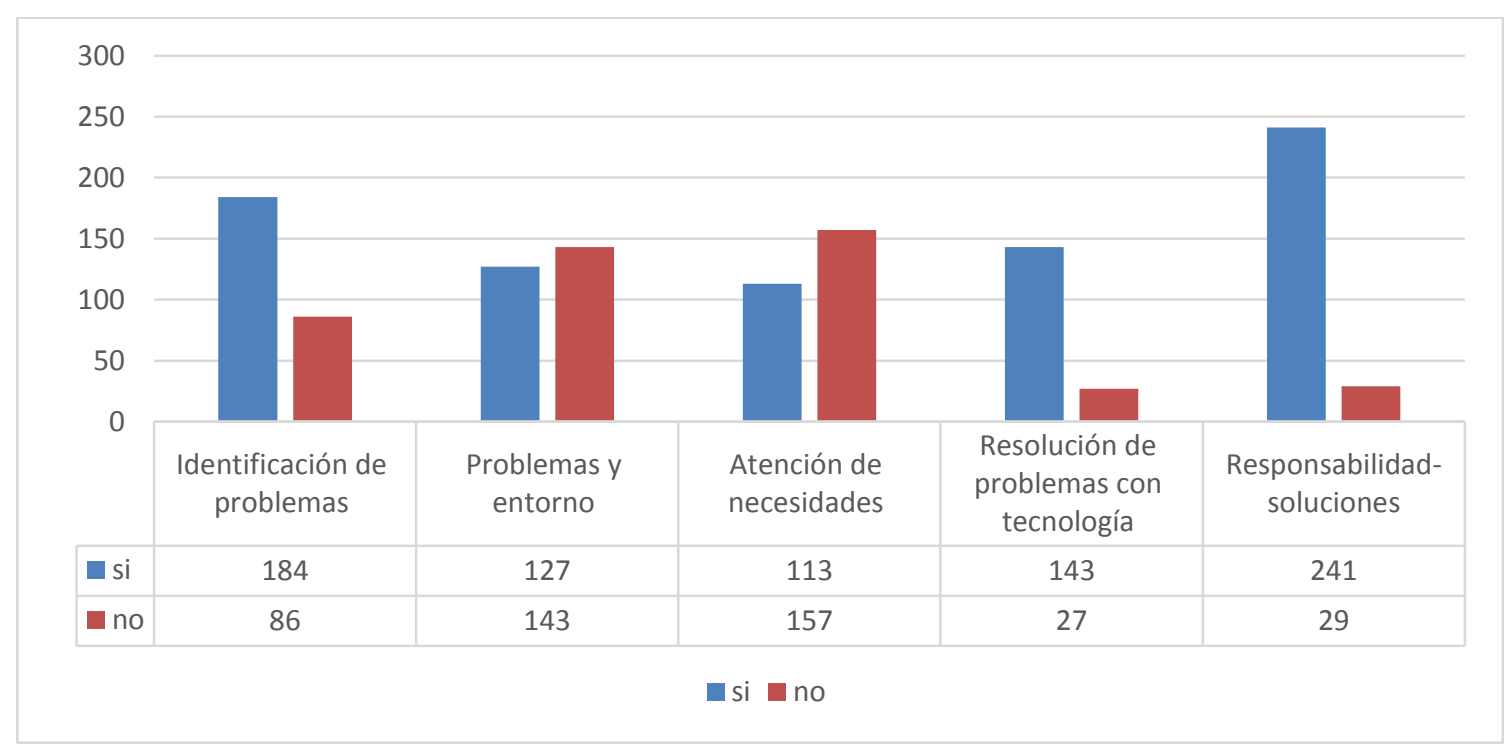

Figura 7. Competencia Propositiva. Elaboración propia (2019).

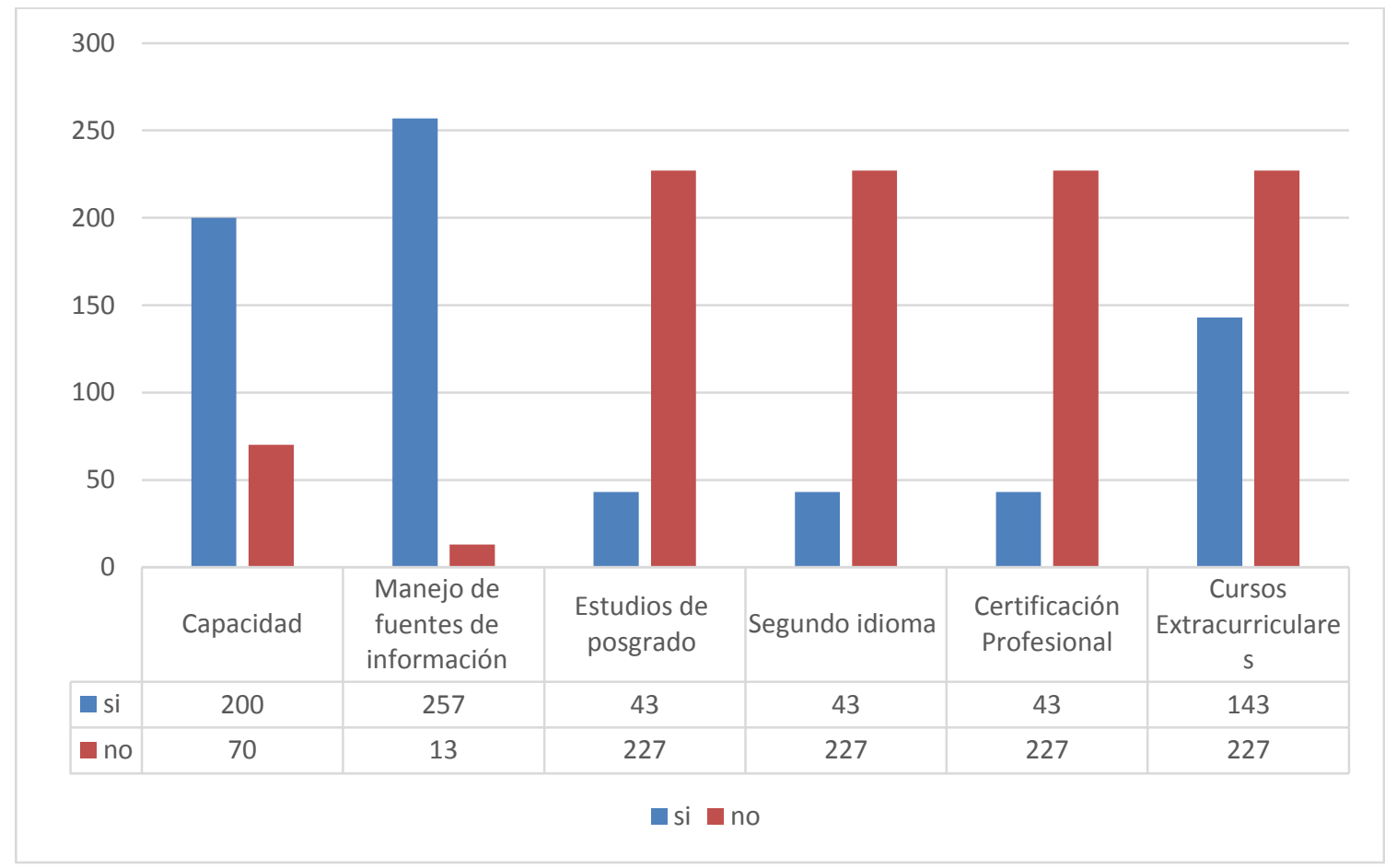

Figura 8. Competencia Investigativa. Elaboración propia (2019.)

Vera, M. A. M., Martínez Méndez, R. \& Martínez Méndez J. G. S.

La certificación profesional y la capacitación, como apoyo al contador público en las competencias que le requiere el mercado laboral. 
Tabla 4

Concentrado de resultados de competencias

\begin{tabular}{|c|c|c|c|c|c|c|}
\hline $\begin{array}{c}\text { Promedio } \\
\text { de } \\
\text { respuestas } \\
\text { positivas }\end{array}$ & Comunicativa & Cognitiva & Indagativa & Argumentativa & Propositiva & Investigativa \\
\cline { 2 - 7 } & $68 \%$ & $69 \%$ & $67 \%$ & $75 \%$ & $60 \%$ & $53 \%$ \\
\hline
\end{tabular}

Fuente: elaboración propia (2019).

La competencia mayormente requerida por los empleadores, con un $75 \%$ de respuestas positivas en promedio, es la argumentativa y la menos requerida es la investigativa; según los resultados presentados en la tabla 4, lo que más requieren los colaboradores de forma específica son personas con iniciativa y lo que menos requieren es opinión externa, como se muestra en la figura 4; la figura 8 ilustra lo relativo a requerimientos de estudios de posgrado, segundo idioma y certificación profesional, con una frecuencia de 43 respuestas positivas. Referente a la capacitación en los resultados se observa equilibrio en la preferencia por contratar personas capacitadas para el manejo de tecnología y la capacitación con actividades extracurriculares, figura 7 y figura 8 respectivamente; la capacitación por estudios de posgrado tiene un requerimiento mínimo por los empleadores según los resultados de la figura 8, misma que muestra los resultados por contratar C.P. certificados y, como ya se mencionó, los empleadores no tienen interés por contratarlos.

Los resultados obtenidos en las variables capacitación y certificación profesional se presentan en las figuras 9 y 10.

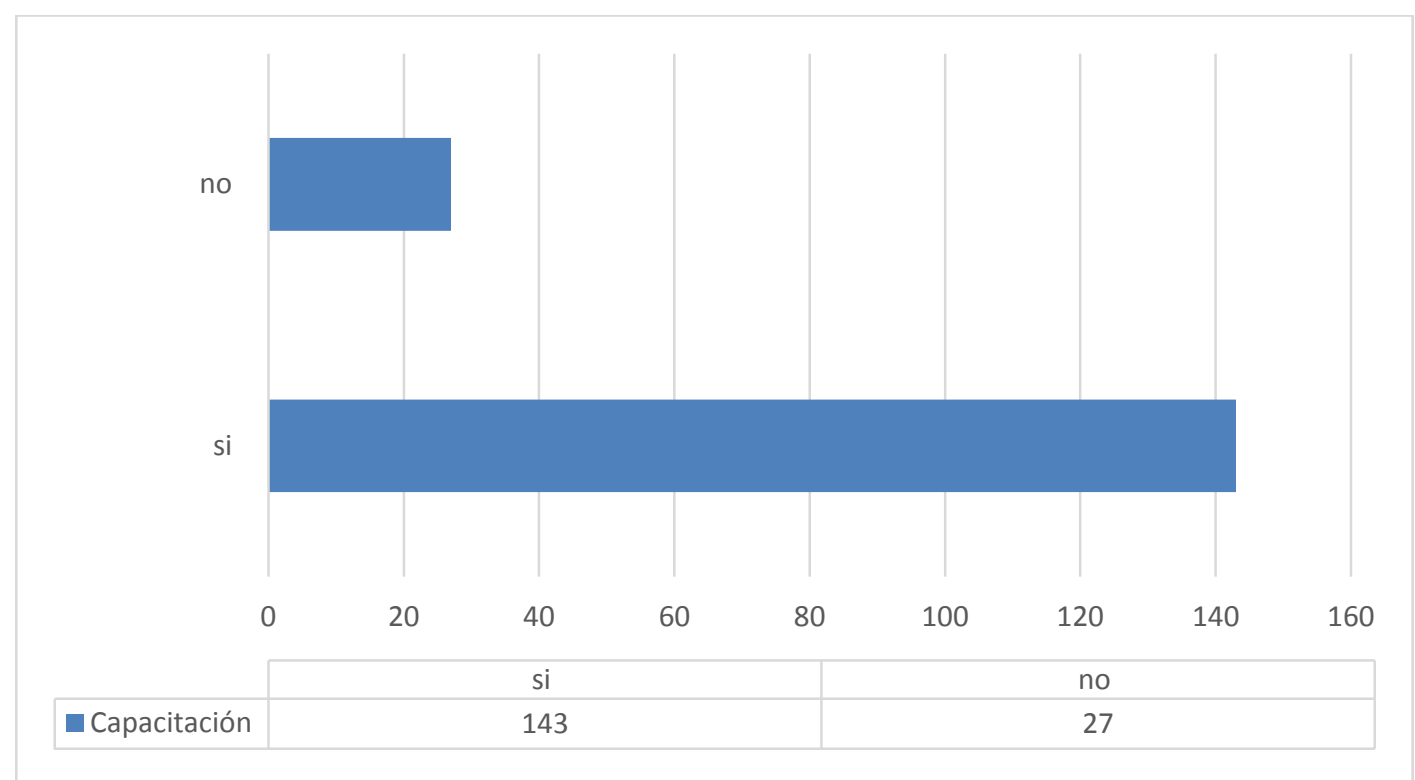

Figura 9. Capacitación. Elaboración propia (2019).

Vera, M. A. M., Martínez Méndez, R. \& Martínez Méndez J. G. S.

La certificación profesional y la capacitación, como apoyo al contador público en las competencias que le requiere el mercado laboral. 


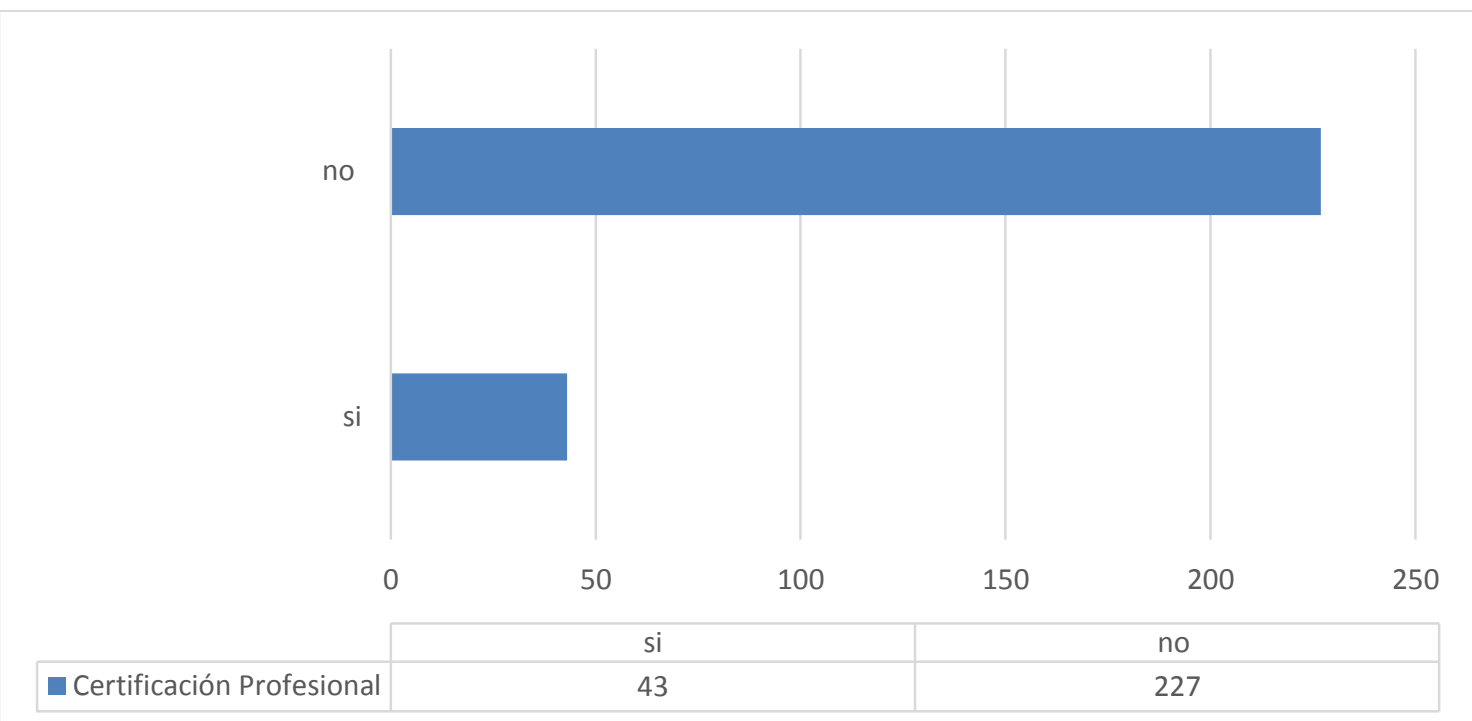

Figura 10. Certificación Profesional elaboración propia (2019).

Respecto a las figuras 9 y 10, complementado con la observación in situ, apreciamos la aceptación de la capacitación y desconocimiento por parte de los empleadores de las ventajas de incorporar a la empresa a un Contador Certificado.

Por lo que señalamos, considerando las variables del trabajo como Hipótesis Generales las siguientes:

1. Las competencias se relacionan significativamente con la capacitación.

2. Las competencias se relacionan significativamente con la certificación profesional.

\section{V.I Prueba de Hipótesis}

Para realizar la prueba de las hipótesis integradas por variables cualitativas dicotómicas consideramos realizarlo con Chi cuadrado, para identificar la relación existente entre las mismas.

Hipótesis estadísticas:

Alternativa:

H1 Las competencias se relacionan significativamente con la Capacitación.

Nula:

HO: Las competencias no se relacionan significativamente con la Capacitación. 
Tabla 5

Prueba de Hipótesis, relación competencias-capacitación.

\begin{tabular}{|l|r|r|r|}
\hline \multicolumn{4}{|c|}{ Pruebas de chi-cuadrado } \\
\hline & Valor & $\mathrm{gl}$ & $\begin{array}{c}\text { Significación } \\
\text { asintótica } \\
\text { (bilateral) }\end{array}$ \\
\hline Chi-cuadrado de Pearson & $270.000^{\mathrm{a}}$ & 15 & .000 \\
\hline Razón de verosimilitud & 373.351 & 15 & .000 \\
\hline Asociación lineal por lineal & 195.060 & 1 & .000 \\
\hline N de casos válidos & 270 & & \\
\hline $\begin{array}{l}\text { a. } 4 \text { casillas (12.5\%) han esperado un recuento menor que 5. El recuento mínimo esperado es } \\
.47 .\end{array}$
\end{tabular}

Fuente: elaboración propia (2019.)

Interpretación. Como el nivel de significancia es menor que $0.05 \quad(0.000<0.05)$, rechazamos la hipótesis nula y aceptamos la hipótesis alternativa; por lo que podemos mencionar que a un nivel de significancia de 0.05 las competencias se relacionan significativamente con la capacitación.

Alternativa

$\mathrm{H} 2$ las competencias se relacionan significativamente con la certificación profesional.

Nula:

HO las competencias no se relacionan significativamente con la certificación profesional.

Tabla 6

Prueba de Hipótesis, relación competencias-capacitación

\begin{tabular}{|l|r|r|r|}
\hline \multicolumn{3}{|c|}{ Pruebas de chi-cuadrado } \\
\hline & \multicolumn{1}{|c|}{ Valor } & \multicolumn{1}{|c|}{ gl } & $\begin{array}{c}\text { Significación asintótica } \\
\text { (bilateral) }\end{array}$ \\
\hline Chi-cuadrado de Pearson & $255.410^{\text {a }}$ & 15 & .000 \\
\hline Razón de verosimilitud & 217.759 & 15 & .000 \\
\hline Asociación lineal por lineal & 68.283 & 1 & .000 \\
\hline N de casos válidos & 270 & & \\
\hline
\end{tabular}

Vera, M. A. M., Martínez Méndez, R. \& Martínez Méndez J. G. S. 
a. 16 casillas $(50.0 \%)$ han esperado un recuento menor que 5 . El recuento mínimo esperado es

.16 .

Fuente: elaboración propia (2019).

Interpretación. Como el nivel de significancia es menor que $0.05 \quad(0.000<0.05)$, rechazamos la hipótesis nula y aceptamos la hipótesis alternativa; por lo que podemos mencionar que a un nivel de significancia de 0.05 las competencias se relacionan significativamente con la certificación profesional.

\section{CONSIDERACIONES FINALES}

Con base en los resultados antes presentados, realizamos la discusión de los mismos de acuerdo con lo señalado por Valera (2019), quien aborda las competencias enfocadas a la profesión contable y así tenemos que respecto a la competencia comunicativa los resultados coinciden en lo relativo a que el C. P. tiene que interactuar con los empresarios y para ello emplear un lenguaje adecuado para comunicarse y considerar que las empresas ya no se inclinan por el trabajo individual, ahora hay la exigencia de trabajo en equipo. Igualmente, hay coincidencia en los resultados de la competencia cognitiva le requiere al C.P. estar bien informado, debido a que la profesión contable en México tiene mayoritariamente el enfoque fiscal y en esa área hay constantes cambios y exigencias por parte de las autoridades fiscales.

Siguiendo con lo señalado por Valera (2019), hay coincidencia en los resultados de la competencia indagativa, exigen buscar información respecto de facturación electrónica, nomina electrónica y contabilidad electrónica, por ejemplo. La competencia argumentativa también coincide con la autora al encontrar resultados que obligan al C.P. el tener conocimientos que faciliten la argumentación de la información que construye, por ejemplo, un adecuado manejo de las Normas de Información Financiera (NIF) facilitará la construcción de la información financiera y le dará argumentos para defender los criterios aplicados.

Asimismo, los resultados de la competencia propositiva concuerdan con lo expuesto con Valera (2009) al mostrar que el C.P. se le requiere apoyar y orientar a la empresa con todo lo relacionado a su profesión y, en su caso, canalizar la situación problemática con el especialista indicado y tener una gran visión de los aspectos contables de forma integral. Finalmente, la competencia investigativa demanda la interacción con los empresarios y para ello emplear un lenguaje adecuado para comunicarse y estar informado y capacitado, conviniendo lo expuesto por la autora ya referida al inicio de este párrafo.

Como conclusiones del trabajo, mencionamos que las competencias son una exigencia actual y se abordan con diferentes enfoques y desde diferentes áreas, lo que hace

Vera, M. A. M., Martínez Méndez, R. \& Martínez Méndez J. G. S. 
necesario en el presente trabajo identificar las competencias que le son requeridas al C.P., mismas que están estrechamente relacionadas con la capacitación, la educación y la certificación profesional del C.P.

Para cerrar las conclusiones, comentamos que en el desarrollo del trabajo no se pudo precisar y constatar para poder señalar que el ingreso del Contador depende de las competencias con las que cuente de manera global, pero es notaria la falta de interés por contratar a C.P. certificados.

El punto anteriormente comentado permite identificar que aún falta de familiarizarse e informar a los empleadores con respecto a competencias, capacitación y certificación del C.P.

Con el desarrollo teórico y la investigación de campo, empíricamente pudimos lograr el objetivo planteado: indagar el apoyo que la capacitación y la certificación profesional aportan al Contador Público para adquirir y fortalecer las competencias que le son requeridas por el mercado laboral. Además de establecer la relación entre las competencias con la capacitación y la certificación profesional de los contadores.

\section{REFERENCIAS}

Alles M. (2010). Desempeño por Competencias Evaluación de 360․․ Editorial GRANICA. México.

Carrión E. (2013). Recursos Humanos y Capital Humano. Escuela de Organización Industrial EOI. Disponible en: https://www.eoi.es/blogs/madeon/2013/03/12/recursos-humanos-ycapital-humano/.Consultado 15 de febrero 2019.

Castillo C. (2016). Importancia de la certificación profesional del capital humano como parte de las competencias de los contadores públicos en el mercado laboral, como apoyo a su mejor desempeño". Tesis para obtener el grado de Maestro en Administración en la Benemérita Universidad Autónoma de Puebla.

Chiavenato I. (2017). Administración de recursos humanos. El capital humano de las organizaciones. Mc Graw Hill. México.

Cordúa, J. (2000). La formación universitaria en la perspectiva del mundo empresarial. En Las nuevas demandas del desempeño profesional y sus implicancias para la docencia universitaria. Centro Interuniversitario de Desarrollo (CINDA). Alfabeta Artes Gráficas. Santiago de Chile.

Ernts \& Joung (2017). Manual del director de Recursos Humanos.

Farías J. (2013). Dirección de capital humano. Trillas. México.

Vera, M. A. M., Martínez Méndez, R. \& Martínez Méndez J. G. S. 
Instituto de Información Estadística y Geografía [IIEG], 2018. Disponible en https://www.iieg.gob.mx/. Consultado el 15 de marzo 2019.

Irigoin, M. (2002). Competencia laboral: manual de conceptos métodos y aplicaciones en el sector salud. Montevideo. Cinterfor - OPS. 252p. II. ISBN 929088-138-0.

Linares y Súarez. (2017). Competencias del contador público: Una mirada desde la Educación Superior y los requerimientos de las PyME comerciales en Bogotá. Teuken Bidikay Vol. 8 № 10 (Medellín, Colombia). Enero - Junio pp. 149-175. Disponible en: https://www.researchgate.net/publication/322930197_COMPETENCIAS_DEL_CONTA...Re cuperado el 30 de mayo 2019.

Tejada J. (2005). El trabajo por competencias en el prácticum: cómo organizarlo y cómo evaluarlo. Revista Electrónica de Investigación Educativa (REDIE). Vol. 7 No. 2. Disponible en: https://redie.uabc.mx/redie/article/view/192/332. Consultado el 26 de febrero 2019.

Valera F. (2009). Propuesta de competencias profesionales para los estudiantes de la carrera de Contabilidad y Finanzas. Cuadernos de Educación y Desarrollo. Vol 1, № 1 (marzo 2009). Centro Universitario "Vladimir I. Lenin". Las Tunas. Disponible en: http://www.eumed.net/rev/ced/01/lvf.htm. Recuperado el 26 de febrero 2019.

Valero, G., Patiño, R. y Duque, O. (2013). Competencias para el programa de Contaduría Pública: una aproximación conceptual. Contaduría Universidad de Antioquia, enero-junio. Vol. 62 $\mathrm{pp}$ 11-36.

Disponible

en: https://aprendeenlinea.udea.edu.co/revistas/index.php/cont/article/download/.../16147. Recuperado el 30 de mayo 2019. 